\title{
An eating disorder-specific model of interpersonal psychotherapy (IPT-ED): Causal pathways and treatment implications
}

\author{
Elizabeth Rieger ${ }^{\mathrm{a}, *}$, Dorothy J. Van Buren ${ }^{\mathrm{b}}$, Monica Bishop ${ }^{\mathrm{b}}$, Marian Tanofsky-Kraff ${ }^{\mathrm{c}}$, \\ Robinson Welch ${ }^{\mathrm{b}}$, Denise E. Wilfley ${ }^{\mathrm{b}}$ \\ a Department of Psychology, The Australian National University, Canberra, Australian Capital Territory, Australia \\ b Department of Psychiatry, Washington University School of Medicine, St Louis, Missouri, United States

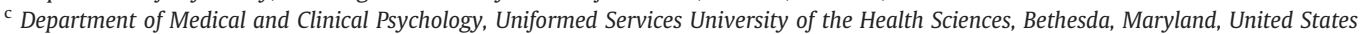

\section{A R T I C L E I N F O}

\section{Article history:}

Received 12 June 2009

Received in revised form 5 February 2010

Accepted 6 February 2010

\section{Keywords:}

Interpersonal psychotherapy

Eating disorders

Interpersonal factors

Maintenance model

\begin{abstract}
A B S T R A C T
Several studies support the efficacy of interpersonal psychotherapy (IPT) in the treatment of eating disorders. Treatment outcomes are likely to be augmented through a greater understanding, and hence treatment targeting, of the mechanisms whereby IPT induces therapeutic gains. To this end, the present paper seeks to develop a theoretical model of IPT in the context of eating disorders (IPT-ED). After providing a brief description of IPT, the IPT-ED model is presented and research supporting its theorized mechanisms is summarized. This model proposes that negative social evaluation plays a pivotal role as both a cause (via its detrimental impact on self evaluation and associated affect) and consequence of eating disorder symptoms. In the final section, key eating disorder constructs (namely, the developmental period of adolescence, clinical perfectionism, cognitive dysfunction, and affect regulation) are re-interpreted from the standpoint of negative social evaluation thereby further explicating IPT's efficacy as an intervention for individuals with an eating disorder.
\end{abstract}

(c) 2010 Elsevier Ltd. All rights reserved.

\section{Contents}

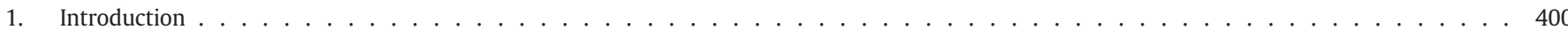

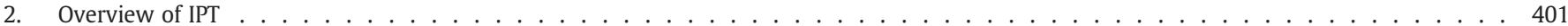

3. Theoretical model of IPT for eating disorders (IPT-ED) . . . . . . . . . . . . . . . . . . . . . . . . . . . . . . . . . . . . 402

3.1. Overview of the IPT-ED model . . . 402

3.2. Negative social evaluation triggers low self-esteem and negative affect . . . . . . . . . . . . . . . . . . . . . . . . . . 403

3.3. Negative social evaluation triggers eating disorder symptoms . . . . . . . . . . . . . . . . . . . . . . . . . . .

3.4. Eating disorder symptoms exacerbate negative social evaluation . . . . . . . . . . . . . . . . . . . . . . . . . . 405

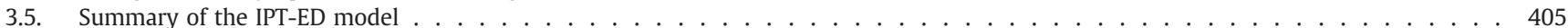

4. The reconceptualization of eating disorder related constructs in social evaluative terms . . . . . . . . . . . . . . . . . . . . 405

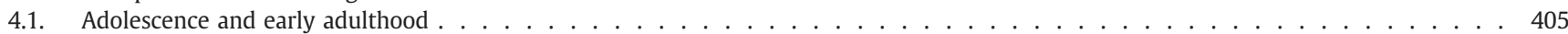

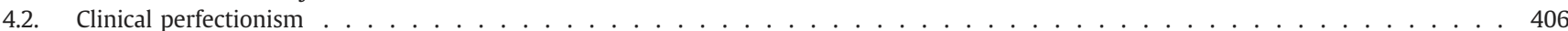

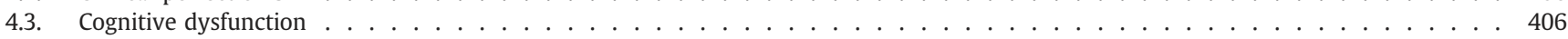

4.4. Affect regulation strategies . . . . . . . . . . . . . . . . . . . . . . . . . . . . . 407

5. Concluding comments . . . . . . . . . . . . . . . . . . . . . . . . . . . . . . . . . . . . . . . . . . . . . 407

References . . . 408

* Corresponding author. Department of Psychology, The Australian National University, Canberra ACT 0200, Australia. Tel.: +612 6125 4208; fax: +61261250499. E-mail addresses: Elizabeth.Rieger@anu.edu.au (E. Rieger),

vanbured@psychiatry.wustl.edu (D.J. Van Buren), bishopm@psychiatry.wustl.edu (M. Bishop), mtanofsky@usuhs.mil (M. Tanofsky-Kraff), welchr@psychiatry.wustl.edu (R. Welch), wilfleyd@psychiatry.wustl.edu (D.E. Wilfley).

\section{Introduction}

Among psychiatric conditions, eating disorders are unique in that their core features-the control of body shape, weight, and eatinghave immense social currency in cultural settings in which thinness 
and/or dietary restraint are highly valued. These varied settings include medieval female saints whose religious tradition venerated suffering and denigrated the flesh (Bell, 1985), Chinese Daoist practices that emphasize fasting as a means of attaining spiritual perfection (Eskildsen, 1998), or the "cult of thinness" of contemporary Western culture (Hesse-Biber, Leavy, Quinn, \& Zoino, 2006, p. 208). The social status to be gained from bodily and dietary control can only be enhanced in societies where the majority of individuals struggle with problems of overweight or obesity (World Health Organization, 1998). That aspects of eating disorder symptomatology are socially prescribed, suggests a central role for interpersonal factors in the development and maintenance of these conditions.

Consistent with an interpersonal formulation of eating disorders, there is abundant evidence highlighting the existence of interpersonal dysfunction in the lives of individuals with an eating disorder (for a review, see Wilfley, Stein, \& Welch, 2003). Moreover, there is support for the efficacy of interpersonal psychotherapy (IPT), an approach that targets interpersonal problems as a means of resolving psychological symptoms (Klerman, Weissman, Rounsaville, \& Chevron, 1984; Weissman, Markowitz, \& Klerman, 2000), in the treatment of eating disorders (e.g., Agras, Walsh, Fairburn, Wilson, \& Kraemer, 2000; Wilfley et al., 1993; Wilfley et al., 2002).

Yet in stark contrast to cognitive behavior therapy (CBT), in which eating disorder-specific adaptations were originally formulated in the 1980 s (e.g., Fairburn, 1985), there is no empirically supported theoretical model of IPT for eating disorders. The insufficient theoretical foundation of IPT is not unique to eating disorders and is partly the legacy of IPT having evolved in the context of treatment outcome evaluation such that questions as to why it is effective have lagged behind questions as to whether it is effective (Stuart \& Robertson, 2003).

Nevertheless, both general (Stuart \& Robertson, 2003) and disorder-specific models of IPT have been proposed, such as IPT for depression (Frank \& Spanier, 1995), dysthymia (Markowitz, 2003), and borderline personality disorder (Markowitz, Skodol, \& Bleiberg, 2006). Attachment theory (Bowlby, 1977) has been described as the theoretical foundation of IPT in that psychological problems are hypothesized to develop when an individual's needs for attachment (i.e., strong affectional bonds with preferred others) are not being met (Stuart \& Robertson, 2003). These bonds "provide opportunities for intimacy, nurturance, validation of self worth, and a sense of connectedness with others" (Frank \& Spanier, 1995, p. 353) and their disruption results in various forms of emotional distress such as anxiety, depression, and anger. However, these attachment-based approaches were not designed to account for the mechanisms by which attachment disturbances elicit eating disorder symptoms as opposed to other forms of psychopathology.

To initiate the process of theory-building in IPT for individuals with an eating disorder, the present paper proposes a theoretical model that seeks to explain IPT's efficacy and to guide its future implementations in this population. After providing a brief overview of IPT, the paper is divided into two sections. The first section presents our theoretical model of IPT for eating disorders (IPT-ED), beginning with an overview of the model followed by a review of the research supporting the theorized mechanisms by which specific interpersonal problems maintain, and are in turn maintained by, eating disorder symptoms. Emphasizing the validating aspects of attachment bonds, it will be argued that negative social evaluation plays a central role in triggering disturbances of the self and hence eating disorder symptoms. Given the primacy of negative social evaluation in our IPT-ED model, the second section provides a reexamination of several key eating disorder relevant constructs (including the developmental stage of adolescence as a risk period for the onset of eating disorders, clinical perfectionism, dysfunctional cognitive processes, and affect regulation strategies) from the perspective of negative social evaluation.

\section{Overview of IPT}

IPT originated as a standardized form of interpersonally-oriented psychotherapy for use in treatment outcome research on depression (Birchall, 1999; Swartz, 1999; Tantleff-Dunn, Gokee-LaRose, \& Peterson, 2004; Weissman, 2007). As with CBT, IPT is typically implemented as a time-limited treatment, consisting of 12 to 20 sessions spanning four to six months (Birchall, 1999; Wilson, 2005). IPT is well tolerated by patients and is easily learned by competent therapists (Birchall, 1999; Crafti, 2002; Tantleff-Dunn et al., 2004). Although the therapist is less directive in IPT than in the behavioral therapies (Apple, 1999), IPT itself is a focused intervention (with a focus on the interrelatedness of interpersonal problems and psychological symptoms) and in this way has come to differentiate itself from traditional, supportive psychotherapy (Tantleff-Dunn et al., 2004). The hallmark of IPT is the completion of a chronological review of the individual's significant life events, fluctuations in mood and self-esteem, and interpersonal processes in order to identify areas of social functioning associated with the development and maintenance of psychological symptoms (Wilfley, MacKenzie, Welch, Ayres, \& Weissman, 2000; Wilfley et al., 2003). Typically, the result of this collaborative formulation is the identification of problems in one or two of the following areas of interpersonal functioning: grief, role transitions, interpersonal role disputes, and interpersonal deficits.

In IPT for eating disorders (Jacobs, Welch, \& Wilfley, 2004; Tanofsky-Kraff \& Wilfley, in press), the problem area of grief is identified when eating disorder symptoms are associated with the loss of a person or a relationship. A role transition is identified as a focus of treatment when eating disorder symptoms are associated with a change in life status. Interpersonal role disputes are addressed in treatment when eating disorder symptoms are related to conflict between the person with the eating disorder and significant others as a result of different expectations about the relationship. The problem area of interpersonal deficits is applied when eating disorder symptoms are associated with poor social skills or repeatedly difficult interactions that yield chronically unsatisfying relationships.

Given its similarities with CBT (time-limited, structured, acceptable, and transferable), yet its distinctive focus on resolving interpersonal difficulties, IPT has served as a comparison treatment in research on bulimia nervosa, binge eating disorder, and anorexia nervosa. IPT has been found to yield comparable recovery rates to CBT in the long-term for bulimia nervosa (Agras et al., 2000; Fairburn et al., 1991) and in both the short- and long-term for binge eating disorder (Wilfley et al., 2002). Research has also demonstrated some advantages of IPT over other psychological treatments (e.g., greater effectiveness than behavioral weight loss treatment and CBT-based guided self-help for individuals with BED who have low self-esteem and high eating disorder psychopathology) (Wilson, Wilfley, Agras, \& Bryson, 2010). However, research also indicates limitations in the use of IPT for the treatment of patients with an eating disorder. In addition to the delayed therapeutic effects of IPT relative to CBT in the treatment of bulimia nervosa (Agras et al., 2000), one study found that IPT yielded significantly poorer post-treatment recovery rates compared to specialist supportive clinical management in the treatment of patients with full or partial syndromes of anorexia nervosa, although there was no significant difference between CBT or IPT in this regard (McIntosh et al., 2005; McIntosh et al., 2006).

Previous research evaluating IPT in the context of eating disorders has typically entailed various limitations in its implementation that are likely to have diminished its therapeutic effects. Among these methodological limitations are the failure to discuss eating disorder symptoms (and hence their connection with interpersonal problems), a prolonged period of assessment in the IPT intervention with a consequently insufficient amount of time for working on change, and the exclusion of strategies that are common to both IPT and CBT from the IPT intervention (and thus its potential attenuation) so as to more 
clearly differentiate IPT from CBT. Indeed, preliminary research suggests that more comprehensive implementations of IPT yield rapid improvements in patients with bulimic eating disorders (Arcelus et al., 2009).

Yet, in addition to procedural considerations, the absence of a comprehensive theoretical model for the use of IPT in the treatment of patients with an eating disorder may have resulted in insufficient guidance regarding the key maintaining interpersonal factors that should be targeted in the aim of resolving eating disorder symptoms. Recent years have witnessed the emergence of integrative approaches which highlight the role of both cognitive and interpersonal factors in the maintenance of eating disorders generally (Fairburn, Cooper, \& Shafran, 2003), and bulimia nervosa (Peterson, Wonderlich, Mitchell, \& Crow, 2004) and anorexia nervosa (Schmidt \& Treasure, 2006) specifically. In providing a more comprehensive interpersonal framework, the IPT-ED model proposed here may thus have relevance for these approaches in addition to its primary focus in informing IPT interventions for eating disorders. Since the IPT-ED model is intended to inform interventions, the emphasis is on interpersonal processes that are theorized to be maintaining the eating disorder, although it is feasible that similar factors are involved in the development of the disorder (Wilfley, Pike, \& Striegel-Moore, 1997).

\section{Theoretical model of IPT for eating disorders (IPT-ED)}

\subsection{Overview of the IPT-ED model}

Our proposed model of IPT for eating disorders (IPT-ED) draws upon longstanding conceptualizations of eating disorders in ascribing a pivotal role to disturbances of the self in the development and maintenance of eating disorder symptoms but adds to these approaches by emphasizing links between disturbances of the self and the individual's experiences and perceptions of his/her social world. Chief among the disturbances of the self that are relevant for eating disorders are negative self evaluation (i.e., negative beliefs regarding one's worth generally or in specific domains) (Tesser, 2003) and poor self-regulation (in particular, ineffective strategies for regulating one's mood) (Baumeister \& Vohs, 2003).

There is extensive theoretical and empirical work linking these disturbances of the self to eating disordered attitudes and behaviors. For instance, in an early account, Bruch (1973) highlighted poor self worth in characterizing anorexia nervosa as "a desperate struggle for a self-respecting identity" (p. 250). Subsequently, self disturbances, particularly low self-esteem and dysfunctional mood regulation, have featured in prominent approaches regarding the etiology and treatment of eating disorders (e.g., Cooper, Wells, \& Todd, 2004; Fairburn et al., 2003; Peterson et al., 2004; Schmidt \& Treasure, 2006) and have empirical support regarding their connection to eating disorder pathology (for reviews see Polivy \& Herman, 2002; Stice, 2002). Uniting these approaches is the assumption that engagement in eating disordered behaviors (i.e., self-starvation, dietary restriction and other weight control strategies, and binge eating) is an attempted adaptive response on the part of the individual to overcome states of negative self evaluation and its associated affect (for discussions regarding the functions of eating disorder symptoms see Cockell, Geller, \& Linden, 2002; Nordbø, Espeset, Gulliksen, Skårderud, \& Holte, 2006; Serpell \& Treasure, 2002; Serpell, Treasure, Teasdale, \& Sullivan, 1999; Vitousek, Watson, \& Wilson, 1998). For instance, the individual might attempt to enhance self-esteem through dieting and other methods of weight control (Cooper et al., 2004), or to escape from aversive states of self awareness through binge eating (Heatherton \& Baumeister, 1991), or to avoid these states entirely through selfstarvation (Schmidt \& Treasure, 2006).

The fundamental premise of our IPT-ED model is that these disturbances of the self, which are hypothesized to trigger and maintain eating disorder symptoms, arise as a result of inadequacies in reciprocal interactions between the individual and the social world. A primary feature of the interpersonal dysfunction relevant to eating disorders is negative social evaluation: our IPT-ED model proposes that the IPT problem areas of interpersonal role disputes, role transitions, grief, and interpersonal deficits are relevant to the maintenance of eating disorder symptoms insofar as they entail a high degree of negative social evaluation, defined as actual or perceived negative feedback regarding one's value to another individual or group. Multiple sources of information concerning an individual's social value exist which may be direct (e.g., critical comments from others) or indirect (e.g., observing one's standing relative to others in the form of social comparison) (Wood \& Wilson, 2003). Moreover, negative social evaluation includes not only overtly negative feedback but also insufficient positive evaluation, with research suggesting that the detrimental effects of neutral feedback (e.g., endorsing a neutral response in rating an individual's desirability as a friend or colleague) may be comparable to those of overtly negative feedback (e.g., endorsing a negative response in rating an individual's desirability as a friend or colleague) (Leary, Haupt, Strausser, \& Chokel, 1998).

The central role of negative social evaluation in the IPT-ED model stems from its primacy in triggering poor self-esteem and negative affect. In terms of inducing negative beliefs and associated affect regarding the self, various theories converge in highlighting the role of negative social evaluation. Approaches to social evaluation tend to conceptualize the construct in terms of two broad dimensions, namely, the degree to which an individual is accepted or rejected by others (variously referred to as the dimension of warmth versus coldness, nurturance versus hostility or love versus attack) and the level of status the individual is accorded by others (often referred to as the dimension of dominance versus submissiveness or control versus emancipate) (Alden, Wiggins, \& Pincus, 1990; Benjamin, Rothweiler, \& Critchfield, 2006; Griffin \& Bartholomew, 1994; Gurtman, 2001). Exemplifying the first approach, sociometer theory (Leary \& Baumeister, 2000) maintains that the primary function of the self-esteem system is to monitor the degree to which one is accepted/liked or rejected/disliked by others, a function that is posited to have evolutionary significance given the survival benefits of social belonging. Highlighting the second approach, dominance theory (Barkow, 1975) proposes that the self-esteem system evolved to monitor an individual's level of status (i.e., prestige, respect, influence, control or attention) within social contexts given the likely association between high status and increased reproductive success (Anderson, John, Keltner, \& Kring, 2001; Anderson, Srivastava, Beer, Spataro, \& Chatman, 2006). According to both sociometer and dominance theories, "self-esteem is essentially an internal, psychological gauge that monitors how well one is faring in interpersonal situations" (Leary, Cottrell, \& Phillips, 2001, p. 898). State self-esteem is held to reflect one's value in the current interpersonal context, while trait self-esteem reflects one's general social value (Leary et al., 2001). In conceptualizing self-esteem as being inherently interpersonal in nature, these theories are exemplars of longstanding interpersonal approaches that have highlighted social influences in the construction of the self (e.g., Mead, 1934).

In the IPT-ED model, we propose that functions pertaining to the self (such as the development and maintenance of self-esteem and associated positive affect), which under optimal conditions are achieved through successful individual-social world relations, come to be performed by the eating disorder. In attempting to fulfill the functions of the self typically met through adaptive interactions with the social world, the eating disorder thus acts as a de facto social agent: engagement in eating disorder behaviors comes increasingly to replace healthy engagement with the social world in the individual's efforts to attain positive self-esteem and affect. It is proposed in the IPT-ED model that eating disorder symptoms in turn exacerbate interpersonal problems, thereby further intensifying the symptoms. Given this formulation of the eating disorder as a substitute for deficiencies in the individual's relations with the social world, IPT 
seeks to re-instate (or create) healthy interactions between the individual and his/her social context so that the eating disorder becomes redundant.

The key premise of our IPT-ED model (i.e., that the disturbances of the self which drive eating disorder symptomatology are triggered and sustained by problematic interpersonal dynamics, particularly negative social evaluation) will be explored in the following subsections. Support will be provided for the model's predictions that interpersonal dysfunction (focusing on negative social evaluation) is related to both disturbances of the self (focusing on low self-esteem and associated negative affect) and to eating disorder symptoms. Evidence will also be presented regarding the premise that the eating disorder in turn results in an exacerbation of interpersonal problems. The basic IPT-ED model is summarized in Fig. 1.

\subsection{Negative social evaluation triggers low self-esteem and negative affect}

There is abundant experimental support for the contention that negative feedback regarding one's social value triggers negative self evaluation and associated affect (Kernis, Cornell, Sun, Berry, \& Harlow, 1993; Leary, et al., 1998; Leary et al., 2001; Swann, Griffin, Predmore, \& Gaines, 1987; Tesser, Crepaz, Collins, Cornell, \& Beach, 2000; Williams, Cheung, \& Choi, 2000; Wood, 1989). For example, Leary et al. (2001) conducted a series of experiments in which they assessed the effects of social acceptance and status on self-esteem to evaluate sociometer and dominance theories respectively. In studies 1 and 2, male and female undergraduate students were randomly allocated to one of four experimental conditions in which they were given bogus feedback regarding their peer-rated level of acceptance (high versus low) and status (high versus low). Level of acceptance was operationalized as the degree to which other students wanted the participant to be a member of their group, while level of status was defined as the degree to which students desired the participant to be a leader of their group. The results indicated that acceptance and status feedback had significant and independent effects on state self-esteem. That is, high acceptance feedback resulted in significantly higher state self-esteem than low acceptance feedback, which remained significant after controlling for the contribution of status feedback. The same pattern of findings was obtained in terms of status feedback.

Non-experimental, yet more ecologically valid studies also support the association between social appraisal and self-esteem/affect. For instance, in a longitudinal study by Srivastava and Beer (2005), undergraduate psychology students participated in four weekly group

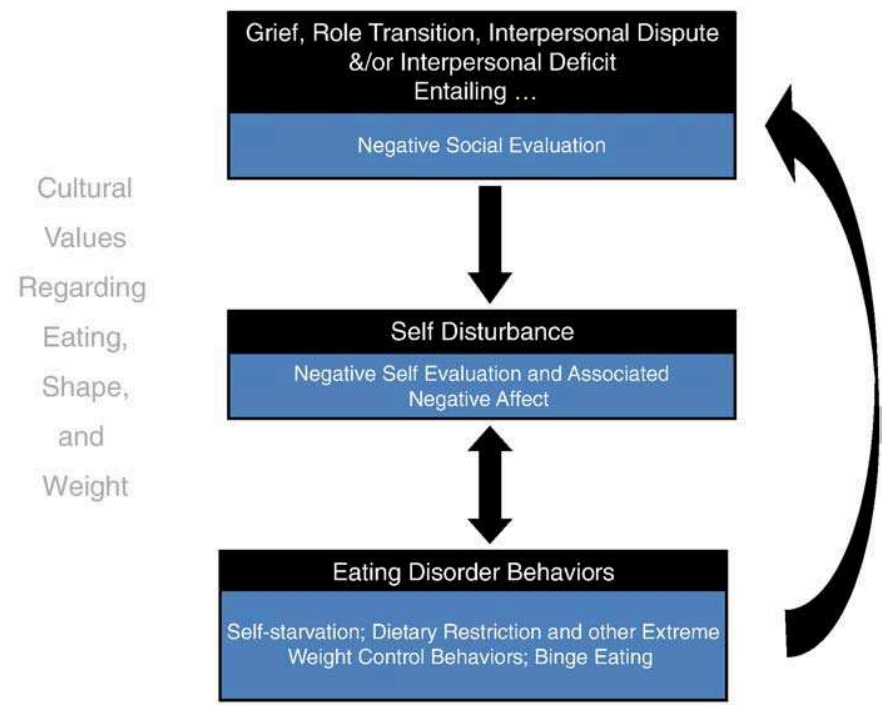

Fig. 1. IPT-ED: A maintenance model of interpersonal factors for eating disorder behaviors. meetings, with self- and peer-ratings regarding likeability assessed after each meeting. It was found that participants who received higher ratings of likeability from others subsequently reported higher levels of selfesteem. In contrast, self-esteem did not predict more positive evaluations from peers over time. Relating negative social feedback to mood disturbance of clinical severity, one study found that perceived criticism from one's spouse measured during hospitalization for depression predicted nine-month relapse rates (Hooley \& Teasdale, 1989). Perceived criticism was unrelated to severity of illness, suggesting that perceived criticism was not simply a marker of more severe depression.

Sociometer and dominance theories maintain that experiences of social acceptance or status respectively underlie fluctuations in selfesteem across all individuals, although those for whom self-esteem is heavily contingent upon social validation may be particularly susceptible to the adverse effects of negative social evaluation on self-esteem and affect (Crocker \& Wolfe, 2001). Nevertheless, statements regarding individual differences in the degree to which self-esteem and mood are affected by social evaluation need to be tempered by several considerations. First, of the seven contingencies of self worth that have been identified among college students, at least four of these have obvious social validation connotations (i.e., Others' Approval, Appearance, Competition with Others, and Family Support domains) (Crocker, Luhtanen, Cooper, \& Bouvrette, 2003). Second, concerns regarding social validation are even relevant in seemingly non-social domains (e.g., academic competence). For instance, the tendency to base self-esteem on approval from others and the tendency to base self-esteem on competency are strongly related among college students, suggesting that individuals may at least partly seek to gain social approval through their achievements in nonsocial domains (Crocker \& Wolfe, 2001). Third, it has been found that the degree to which self-ratings regarding one's success in a range of domains (i.e., competence, physical attractiveness, material wealth, and sociability) are correlated with global self-esteem is significantly greater if the individual believes that level of success in the domain results in higher approval or disapproval from others (MacDonald, Saltzman, \& Leary, 2003). Finally, the effects of acceptance and status feedback on self-esteem reported by Leary et al. (2001) were not moderated by the degree to which participants reported that their self-esteem was contingent upon such feedback. In summary, all individuals are hypothesized to experience deficits in self-esteem as a result of negative social feedback (or poor performance in other domains for which social approval is relevant). While these effects may be more pronounced among those for whom social validation is a primary basis of their self-esteem, this is not invariably the case (as indicated in the findings obtained by Leary et al. (2001)).

\subsection{Negative social evaluation triggers eating disorder symptoms}

The IPT-ED model proposed here contends that disturbances in self evaluation and affect triggered by negative social evaluation result in eating disorder symptoms. While few experimental studies have been conducted to assess the causal role of negative social evaluation in triggering eating disorder symptoms, those studies that have been undertaken are supportive of such a role (Baumeister, DeWall, Ciarocco, \& Twenge, 2005; Oliver, Huon, Zadro, \& Williams, 2001; Stroud, Tanofsky-Kraff, Wilfley, \& Salovey, 2000; Tanofsky-Kraff, Wilfley, \& Spurrell, 2000; Tuschen-Caffier \& Vögele, 1999). For instance, in an experimental manipulation of peer rejection, male and female undergraduate psychology students participated in small group discussions and were then given bogus feedback as to whether or not they had been selected by their peers to work with (Baumeister et al., 2005). In a subsequent taste-test, participants who believed their peers had rejected them ate significantly and substantially more cookies $(M=9)$ compared to those who believed their peers had accepted them $(M=4)$. Moreover, among those in the rejection condition, higher negative mood was associated with a higher number 
of cookies consumed. Experimental paradigms in which participants engage in conflict or are ostracized (i.e., ignored and excluded) by their peers have also been found to result in a significantly higher amount of food consumed during a taste-test in vulnerable individuals (i.e., those high in restraint or disinhibition) (Oliver et al., 2001; Stroud et al., 2000; Tanofsky-Kraff et al., 2000). Utilizing a clinical sample, another study compared the responses of participants with bulimia nervosa to both high- and low-restraint controls after participating in a guided imagery task in which they were asked to identify with a woman who has been left by her boyfriend at a party (Tuschen-Caffier \& Vögele, 1999). Those in the bulimia nervosa group reported significantly greater feelings of insecurity and increased desire to binge during the task compared to both control groups. These differences were not apparent on a task of cognitive ability, thus suggesting a possibly unique position for interpersonal stress among individuals with an eating disorder. However, since the control condition entailed participants engaging in a simple cognitive task, it is not clear whether the difference between the interpersonal and control conditions was due to the negative interpersonal aspects of the guided imagery task or simply its aversive nature.

Expanding upon the dearth of experimental work, correlational studies support the relationship between negative social evaluation and eating disorder symptoms. For instance, poorer quality of friendships (e.g., low perceived acceptance), higher conflict with parents, lower maternal intimacy (e.g., low scores on the item "My mother accepts me no matter what I do"), and lower male partner satisfaction with the relationship have each been found to be associated with increased body image concerns among adolescent or adult females (Boyes, Fletcher, \& Latner, 2007; Gerner \& Wilson, 2005; May, Kim, McHale, \& Crouter, 2006). Among clinical cases, various indices of parental disapproval (e.g., criticism, arguments, high demands, and minimal affection) prior to the development of an eating disorder have been found to be significantly higher among those with anorexia nervosa (Fairburn, Cooper, Doll, \& Welch, 1999; Pike et al., 2007), bulimia nervosa (Fairburn, Welch, Doll, Davies, \& O'Connor, 1997), and binge eating disorder (Fairburn et al., 1998; Striegel-Moore et al., 2005) compared to healthy and/or psychiatric controls. In addition, a higher level of maternal criticism has been found to be a strong predictor of poorer treatment response among adolescent patients with an eating disorder, outperforming other variables such as diagnosis, body mass index, or duration of illness in this regard (van Furth et al., 1996). Observational studies are consistent with these self-report studies in demonstrating higher levels of destructive communication (e.g., blame) and lower levels of intimacy (e.g., the expression of closeness, support, and validation) between mothers and their daughters with eating disorder symptoms compared to control mother-daughter dyads (Lattimore, Wagner, \& Gowers, 2000; Maharaj, Rodin, Connolly, Olmsted, \& Denis, 2001).

Studies employing ecological momentary assessment have the advantage of providing information regarding the temporal sequencing of events and thus provide stronger evidence for the causal role of negative social evaluation in triggering eating disorder behaviors (Okon, Greene, \& Smith, 2002; Steiger, Guavin, Jabalpurwala, Séguin, \& Stotland, 1999). The study by Steiger et al. (1999) has particular relevance for assessing the IPT-ED model since it simultaneously examined the associations between social interaction, self-esteem, mood, and binge eating. In this study, current and recently recovered patients with bulimia nervosa and healthy control women were asked to record the tone of their social interactions (e.g., accepting/ rejecting) and accompanying self evaluation, mood, and eating behaviors over a 6 - to 28 -day period. Patients with active bulimia nervosa rated the tone of social interactions as significantly more negative in the period preceding a binge eating episode compared to the interaction tone on binge-free days. Moreover, across all groups, self criticism increased and mood decreased as the interaction tone worsened. Finally, levels of self criticism during pre-binge social interactions were higher than those on binge-free days. Together, then, the findings from this study are consistent with the predictions of the IPT-ED model that deficits in self-esteem induced by negative social evaluation trigger eating disordered behavior.

Several studies utilizing structural equation modelling have also simultaneously examined the constructs of the IPT-ED model (i.e., negative social evaluation, low self acceptance, and eating disorder symptoms) and have provided support for the theorized associations between these constructs (McClintock \& Evans, 2001; Perry, Silvera, Neilands, Rosenvinge, \& Hanssen, 2008). For instance, McClintock and Evans (2001) found that the association between a fear of negative evaluation from others and eating disorder symptoms among collegeaged women was mediated by low self acceptance.

Thus far the focus has been on general negative feedback. However, an area of negative social evaluation that is likely to have particular relevance in driving eating disorder symptoms (as opposed to alternative clinical manifestations of negative self-esteem and mood such as depression) is negative feedback regarding one's shape, weight, or eating. Indeed, it may be that general negative feedback is only related to eating disorder symptoms among vulnerable individuals, as several studies have found (Oliver et al., 2001; Stroud et al., 2000; Tanofsky-Kraff et al., 2000; Tuschen-Caffier \& Vögele, 1999). In particular, general negative social evaluation may trigger eating disorder symptoms among those for whom beliefs regarding the self and body shape/weight are strongly linked (Fairburn et al., 2003; Geller, Johnston, \& Madsen, 1997; Vitousek \& Hollon, 1990). For these individuals, challenges to self-esteem will have pronounced implications for body-esteem, with body dissatisfaction in turn triggering engagement in eating disorder behaviors such as maladaptive weight control behaviors and binge eating. In addition to shape- and weightbased self worth, outcome expectancies (i.e., beliefs regarding the consequences of engaging in eating, shape, and weight related behaviors such as the belief that eating is helpful in managing negative affect or that social acceptance and self-esteem can be enhanced through attaining thinness) are also likely to play a role in the translation of general negative social evaluation and self-esteem into eating disorder symptoms (Hohlstein, Smith, \& Atlas, 1998). This expanded version of our IPT-ED model is shown in Fig. 2.

In terms of negative social evaluation specific to eating, shape, and weight (as opposed to general negative social evaluation), one study examined the eating- and body-related attitudes and behaviors of fourth- and fifth-grade school-girls and boys as well as their mothers and fathers (Smolak, Levine, \& Schermer, 1999). It was found that the more frequently mothers reported mentioning their child's weight to the child, the more likely the child was to have made weight loss

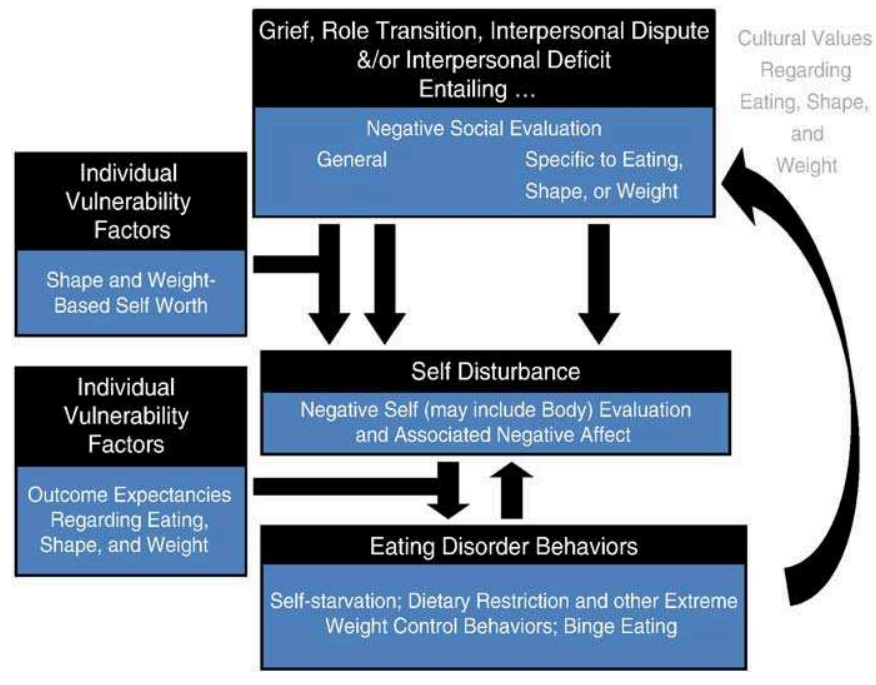

Fig. 2. The expanded IPT-ED model: The role of individual vulnerability factors. 
attempts, to feel less satisfied with his/her body, and to be concerned about weight gain. In women, failed attempts at dieting only predict an increase in depressed mood among those who report higher levels of social disapproval for their weight (Oates-Johnson \& Clark, 2004). Including each of the key components of the IPT-ED model, Wade and Lowes (2002) found that the relationship between family comments about shape or weight and overconcern with shape and weight among adolescent females was mediated by self-esteem. Among clinical cases, critical comments from family members regarding one's shape, weight, or eating are reported to have occurred significantly more often in the period preceding their disorder by individuals with anorexia nervosa (Fairburn et al., 1999), bulimia nervosa (Fairburn et al., 1997), and binge eating disorder (Fairburn et al., 1998) compared to healthy controls, and may distinguish individuals with an eating disorder from psychiatric controls (Fairburn et al., 1997; Fairburn et al., 1998). Premorbid experiences of teasing regarding one's shape, weight, eating, or appearance may also be higher among those with an eating disorder in comparison with healthy controls (Fairburn et al., 1997; Fairburn et al., 1998).

Thus far the bulk of the research reviewed has entailed direct feedback regarding an individual's social worth through experiences of acceptance/rejection by others. Yet, as stated, information regarding an individual's social value can also be gained through social comparison. In an experimental evaluation of the role of social comparison in triggering body dissatisfaction, female undergraduate students were randomly allocated to briefly interact with a confederate who represented the thin ideal or to one who had average body dimensions (Krones, Stice, Batres, \& Orjada, 2005). Participants were told that they were ostensibly taking part in a study assessing their dating desirability and their photos, weights, and bodily dimensions were taken to heighten the salience of body shape/weight. Despite the brevity of the interaction, participants exposed to the thin ideal confederate subsequently reported significantly higher body dissatisfaction relative to those exposed to the average-weight confederate. Correlational studies also support an association between social comparisons regarding body shape/weight and eating disordered attitudes and behaviors (Paxton, Schutz, Wertheim, \& Muir, 1999; Shroff \& Thompson, 2006). For instance, a greater tendency to compare one's body to others is associated with higher body concerns, dietary restraint, extreme weight loss behaviors (e.g., vomiting), and bulimic tendencies among adolescent girls (Paxton et al., 1999).

\subsection{Eating disorder symptoms exacerbate negative social evaluation}

In the IPT-ED model, we further propose that the eating disorder symptoms induced by negative social evaluation in turn result in an exacerbation of negative feedback regarding one's social worth. In this manner, the sufferer becomes caught in a self-perpetuating cycle of deteriorating interpersonal functioning and eating disorder symptomatology.

Various theorists have highlighted how eating disorder symptoms may induce negative evaluation from others. For instance, parents and clinicians may become critical and controlling in the face of unproductive attempts to encourage the individual to eat; family members may become resentful of the sufferer as the disorder comes to dominate family life; and personality and mood changes (e.g., social withdrawal and increased irritability) arising from the disorder may elicit negative reactions from others (Eisler, 2005; Nielsen \& Bará-Carril, 2003; Schmidt \& Treasure, 2006; Vitousek et al., 1998). The emphasis on externalizing the disorder (i.e., attributing difficulties to the disorder rather than the sufferer) in family therapy approaches is an attempt to diminish these negative family interactions (Eisler, 2005; Lock \& le Grange, 2005), the helpfulness of which is noted by patients and parents alike (Poser, 2005a,b).

Minimal research has been conducted to evaluate the role of eating disorder symptoms in triggering negative social evaluation. For example, while numerous studies have demonstrated higher levels of dysfunction in the families and marital relationships of individuals with an eating disorder compared to controls, the cross-sectional nature of these studies precludes any determination as to whether these disturbances are a cause and/or a consequence of the disorder (Eisler, 1995; Van den Brouke, Vandereycken, \& Norré, 1997; Van Buren \& Williamson, 1988). The ecological momentary assessment paradigm adopted by Steiger et al. (1999) to track social interactions and binge eating episodes in patients with bulimia nervosa revealed that the tone of social interactions was reported by patients to be significantly worse (e.g., more rejecting, hostile, and critical) both before and after a binge eating episode compared to binge-free days. These findings thus provide initial support for our contention in the IPT-ED model that social interactions characterized by rejection both trigger and are triggered by eating disorder behaviors.

\subsection{Summary of the IPT-ED model}

According to the IPT-ED model we have developed, negative feedback regarding an individual's social worth triggers eating disorder symptoms via its detrimental effect on self-esteem and associated affect. Engagement in eating disorder behaviors is a response to negative social evaluation that is in turn intensified as a result of the eating disorder. In the context of worsening social evaluation, eating disorder behaviors may be perceived by the individual to be a more reliable source of esteem and affect regulation than that provided through self-social world interactions. Engaging in eating disorder behaviors thus comes to increasingly supplant more constructive attempts at engagement in the social world. As a treatment, IPT therefore aims to assist the patient to develop affirming relationships that provide a viable alternative to the eating disorder in the attainment of positive esteem and affect.

\section{The reconceptualization of eating disorder related constructs in social evaluative terms}

In giving primacy to negative social evaluation in the maintenance of eating disorder symptoms, a key implication of the IPT-ED model is the need to broaden previous understandings of various eating disorder relevant constructs so as to acknowledge the role of social evaluative concerns. Among these are the mechanisms by which the adolescent period, clinical perfectionism, cognitive dysfunction, and affect regulation strategies are involved in the maintenance of eating disorders.

\subsection{Adolescence and early adulthood}

Given their age of onset, both anorexia nervosa and bulimia nervosa have long been conceptualized as disorders arising from difficulties in transitioning from childhood to adolescence and early adulthood. Perhaps best known among these approaches, Crisp (1980) proposed that the prepubertal body state characterizing anorexia nervosa was a retreat from the maturational challenges of adolescence including separation from the family, identity formation, and sexuality.

According to the IPT-ED model, a primary aspect of adolescence that encourages engagement in eating disorder behaviors is the altered social context and its attendant shifts in the determination of the adolescent's self worth. Specifically, while parental and other familial relationships remain salient, adolescence is characterized by the growing importance of peer interactions, including those with individuals of the opposite sex (Collins \& Steinberg, 2006). For example, even excluding time spent in the classroom, high school students spend more than double their time with peers compared to adults (Rubin, Bukowski, \& Parker, 1998). With the increasing dominance of peer culture, it is not surprising that the degree to which peer approval predicts global self-esteem increases from late 
childhood to early adolescence, emerging as a strong predictor of selfesteem and depressive affect (Harter, 2006).

A key distinguishing feature of parental and peer relationships is the criteria used to evaluate an individual's worth. That is, relative to parental approval, perceptions regarding one's level of peer approval are more strongly related to one's perceived physical attractiveness (Harter, 1999). Believing that peer approval (particularly from males) can be attained through thinness (e.g., being thinner means that "I would be more popular amongst my male friends") has been found to be associated with higher body dissatisfaction, importance of shape and weight, and restrained eating among adolescent girls (Gerner \& Wilson, 2005). Moreover, the transition into this strongly appearancebased peer milieu occurs at a time when the individual experiences a heightened concern with the appraisals of others: beginning in early adolescence, individuals become "morbidly preoccupied with what others think of them" (Harter, 2006, p. 541).

While the increasing impact of peer approval (and hence appearance concerns) on self-esteem is a normative liability of adolescence, adolescent girls occupying peer networks in which appearance concerns are salient have been found to be at increased risk of developing eating disordered attitudes and behaviors (Paxton et al., 1999; Shroff \& Thompson, 2006). For example, Paxton et al. (1999) found that 15-16 year old girls reported comparable levels of body image concern, dietary restraint, and the use of extreme weight loss behaviors to the girls in their own friendship group. In addition, perceptions of the behaviors and attitudes of friends towards body image and weight control were associated with an individual's own levels of body image concern, dietary restraint, extreme weight loss behaviors, and bulimic tendencies. Providing some support for the causal role of these peer influences, a prospective study found that girls' perceptions of a higher desire for thinness among their peers predicted their own greater desire for thinness, lower appearance satisfaction, and poorer self-esteem one year later (Dohnt \& Tiggemann, 2006).

To summarize, in the IPT-ED model we postulate that adolescence is a period of increased risk for eating disorders since this is a time in which (i) self-esteem is particularly influenced by social evaluation, (ii) peer acceptance becomes increasingly important for self-esteem; and (iii) appearance is seen to be a strong basis of peer acceptance (especially from potential romantic partners). The salience of appearance is magnified for adolescents occupying "weight/shape preoccupied subcultures" (Paxton et al., 1999, p. 255), thus placing these adolescents at increased risk for an eating disorder.

\subsection{Clinical perfectionism}

The construct of clinical perfectionism appears to be more relevant for anorexia nervosa and bulimia nervosa compared to binge eating disorder. For instance, in retrospective reports, perfectionism has been found to be significantly higher in the period preceding the development of both anorexia nervosa (Fairburn et al., 1999) and bulimia nervosa (Fairburn et al., 1997) compared to the reports of healthy controls and, for anorexia nervosa, compared to the reports of psychiatric controls. In contrast, elevated levels of premorbid perfectionism have not been found among individuals with binge eating disorder (Fairburn et al., 1998).

There has been debate regarding whether clinical perfectionism in the context of eating disorders is best conceptualized as a predominantly intrapersonal phenomenon (Shafran, Cooper, \& Fairburn, 2002 , 2003) or whether interpersonal factors are also relevant (Hewitt, Flett, Besser, Sherry, \& McGee, 2003). Adopting an intrapersonal approach, the definition of clinical perfectionism in eating disorders suggested by Shafran et al. (2002) includes the pursuit of self-imposed, personally demanding standards of performance in the domain of eating, shape, or weight despite the occurrence of adverse consequences.
Our IPT-ED model expands upon this definition by proposing that the personally demanding standards of performance in the domain of eating, shape, or weight adopted by individuals with anorexia nervosa and bulimia nervosa (e.g., the pursuit of an unrealistically thin physique) are not arbitrarily selected but are precisely chosen because of their implications for social evaluation. Altering one's physical form is an unavoidably public domain of performance: compared to other aspects of the self, the physical self is unique in that it is "an omnipresent feature of the self, it is always on display for others to observe" (Harter, 1999, p. 160). Moreover, there is an abundant literature attesting to the social rewards and punishments for thinness and fatness respectively (HesseBiber et al., 2006; Puhl \& Brownell, 2003). Since the domain of bodily control is both public and socially valued, it is proposed in the IPT-ED model that the potential for social rewards is part of the core phenomenon of perfectionism in eating disorders (contrary to the position of Shafran et al. (2003) who maintain that interpersonal processes are a possible, rather than necessary, feature).

Given its wide endorsement as the contemporary Western ideal of female attractiveness, the positive social evaluation to be gained from attaining the unrealistically thin physique pursued by many individuals with an eating disorder is readily apparent. Yet seemingly paradoxical is the potential for social validation stemming from the extreme levels of emaciation characteristic of many individuals with anorexia nervosa: severe emaciation is more likely to elicit strong negative, rather than positive, responses from others (e.g., disapproval, fear, despair, horror, and disgust) (Schmidt \& Treasure, 2006).

Several possibilities may account for the ongoing pursuit of emaciation in the face of intense social disapproval. Among these is the maintaining role of negative social feedback whereby, as stated previously, the deficits in self-esteem triggered by such disapproval further intensify engagement in activities (such as weight loss) designed to enhance self-esteem. Another mechanism may be the ambivalence of the feedback sufferers receive from others: amidst the negative feedback may also be communications of greater warmth, nurturance, and responsiveness (i.e., social acceptance) and/or a greater degree of influence or attention accorded the individual (i.e., social status). Finally, while direct feedback from others may be negative, social comparison processes may provide an alternative source of feedback regarding one's social standing (e.g., in the words of one patient, "I felt I was in a better mood when I didn't eat ... I compared myself to other people and then I felt privileged that I could control myself when tempted to eat" [Nordbø et al., 2006, p. 560]). The standards of performance pursued by the sufferer will therefore be partly influenced by the individuals or groups selected for social comparative purposes: if the comparison standard is that of athletes, dancers, models, family members with anorexia nervosa, or other patients with anorexia nervosa, for instance, then the demanding standards of performance characterizing perfectionism will be extreme indeed. It has been proposed that the tendency to make such upward social comparisons (i.e., selecting to compare oneself with those who are superior to oneself in the relevant domain) is particularly likely among those engaging in social comparison for self-improvement (rather than self evaluation) purposes, with the upward comparison providing a source of inspiration (Wood, 1989). For those with a defective sense of self (induced, according to the IPT-ED model, through ongoing experiences of negative social evaluation), an awareness of the need for self-improvement may be pronounced. In sum, in the IPT-ED model we contend that the pursuit of personally demanding standards despite the occurrence of adverse consequences is maintained by direct or indirect (i.e., social comparison) sources of social validation.

\subsection{Cognitive dysfunction}

Of the four problem areas targeted in IPT, interpersonal deficits is unique in that it does not refer to an acute social stressor (i.e., an interpersonal role dispute, role transition, or grief) but refers instead to difficulties within the individual that impede his/her ability to 
establish and maintain healthy relationships with others. In identifying these difficulties, our IPT-ED model places primacy on dysfunctional cognitive processes regarding negative social evaluation, namely, rejection sensitivity. Indeed, Stuart and Robertson (2003) recommend a change in nomenclature from interpersonal deficits to interpersonal sensitivity, given that sensitivity to negative feedback from others is a key characteristic of those presenting with poor social networks.

The constructs of 'rejection sensitivity' and 'fear of negative evaluation' have been similarly defined and operationalized in the Rejection Sensitivity Questionnaire and Fear of Negative Evaluation Scale, respectively, as the tendency to anxiously anticipate negative feedback from others (Downey \& Feldman, 1996; Watson \& Friend, 1969). Both constructs have been found to have negative implications for the individual's interpersonal functioning. For instance, experimental and correlational studies have shown that individuals high in rejection sensitivity are prone to interpreting ambiguous social events as entailing rejection (Downey \& Feldman, 1996). In addition, rejection sensitivity is hypothesized to be associated with overreactions to rejection, perhaps since self worth is excessively contingent upon approval from others. For example, an observational study revealed that women high in rejection sensitivity displayed a significantly higher number of negative behaviors when discussing a conflict issue with their partner compared to women low in rejection sensitivity even after controlling for the partner's level of anger (Downey, Freitas, Michaelis, \& Khouri, 1998). Moreover, expectations regarding rejection may act in a self-fulfilling manner in that the negative behaviors displayed by women high in rejection sensitivity during the conflict interaction in turn predicted their partner's postinteraction anger after controlling for a large number of potentially confounding variables such as the partner's own level of rejection sensitivity, relationship satisfaction and commitment, and negative conflict behaviors (Downey et al., 1998). Longitudinally, rejection sensitivity assessed prior to the commencement of a relationship has been found to predict relationship termination within a year (e.g., $44 \%$ of relationships in which the female partner was high in rejection sensitivity had ended compared to $15 \%$ of couples in which the woman was low in rejection sensitivity) (Downey et al., 1998).

Given the greater tendency of individuals who are high in rejection sensitivity to perceive and react to negative social evaluation, and given the primacy accorded negative social evaluation in the IPT-ED model, it is predicted that such individuals will be more susceptible to eating disorder symptoms. Supporting this prediction, Steiger et al. (1999) found that women with a recent or current diagnosis of bulimia nervosa were more prone to experiencing increases in self criticism following negative social interactions compared to healthy controls, thus suggesting increased levels of rejection sensitivity in women with eating disorders. In another study, a fear of being negatively evaluated by others was found to be associated with a greater drive for thinness among young women, and to predict increases in bulimic tendencies over time (Gilbert \& Meyer, 2005). In interpreting their findings, and consistent with the IPT-ED model, Gilbert and Meyer (2005) propose that individuals who fear negative evaluation from others may become overconcerned with their shape and weight and use dietary restriction to enhance their likelihood of acceptance by others. If their fears of rejection are not allayed, bulimic tendencies may develop as a means of regulating the negative affect associated with rejection expectancies. Finally, given the theorized role of social evaluative concerns in the IPT-ED model and the centrality of these concerns for individuals with social anxiety disorder, it is perhaps not surprising that there is a high level of comorbidity between these conditions, with social anxiety disorder frequently found to have the highest occurrence of all anxiety disorders in individuals with an eating disorder and to pre-date the onset of an eating disorder in a substantial number of cases (Godart, Flament, Lecrubier, \& Jeammet, 2000; Hinrichson, Wright, Waller, \& Meyer, 2003; Laessle, Wittchen, Fichter, \& Pirke, 1989; Piran, Kennedy, Garfinkel, \& Owens, 1985).

\subsection{Affect regulation strategies}

Affect regulation refers to the process by which individuals attempt to alter the type, intensity, and expression of emotions and mood states (Gross, Richards, \& John, 2006). There is abundant support for the contention that eating disorder behaviors function as strategies to escape, avoid, or minimize negative affect (Burton, Stice, Bearman, \& Rohde, 2007; Cockell et al., 2002; Nordbø et al., 2006; Serpell \& Treasure, 2002; Serpell et al., 1999).

According to the IPT-ED model proposed here, attempts to avoid negative social evaluation on the part of individuals with an eating disorder mean that they are, first, more likely to experience negative affect stemming from their social interactions and, second, less likely to utilize social support as a means of regulating their affect. Beginning with the former, eating disorders and the severity of eating disorder symptoms have been found to be associated with the tendency to inhibit the expression of distress and to prioritize the needs of others over the self (Geller, Cockell, Hewitt, Goldner, \& Flett, 2000; Waller et al., 2003), which has been attributed to a desire to avoid rejection and maintain interpersonal relationships (Jack \& Dill, 1992). Suppressing the expression of one's emotions and needs is a primary component of false self behaviors in which the individual's authentic thoughts, feelings, and behaviors are supplanted by displays designed to secure the approval of others (Harter, 1999). Unfortunately, this tendency to 'silence the self has been found to predict poorer self-esteem and increased dysphoria (Besser, Flett, \& Davis, 2003; Cramer, Gallant, \& Langlois, 2005; Gross \& John, 2003), perhaps since self-silencing individuals are left to ruminate on their negative internal states, fail to obtain disconfirmatory evidence regarding the perceived unacceptability of their self ( since the true self remains concealed), are aware of their inauthenticity and isolation from others, and/or the precipitating interpersonal problem has not been addressed and thus remains unresolved (Gross \& John, 2003; Nolen-Hoeksema, 1991; Reijntjes, Stegge, Terwogt, Kamphuis, \& Telch, 2006).

It is further proposed that individuals with an eating disorder seek to alleviate these states of negative self awareness and affect through the solitary regulatory strategies of weight control and/or binge eating behaviors rather than utilizing socially interactive strategies, again due to their social evaluative concerns. Several studies have found that the social networks of individuals with an eating disorder are more impoverished in terms of the size and perceived levels of emotional and practical support compared to control participants (Grissett \& Norvell, 1992; Tiller et al., 1997). Moreover, patients with an eating disorder report lower levels of desired social support compared to controls (Tiller et al., 1997), perhaps due to concerns that revealing perceived negative aspects of the self will result in rejection or a loss of status. Overall, our IPT-ED model highlights the importance of social evaluative concerns in both the need for, and the selection of, affect regulation strategies in individuals with an eating disorder.

\section{Concluding comments}

Due to the relative paucity of research (particularly utilizing experimental designs) investigating interpersonal factors and eating disorders, the proposed IPT-ED model is necessarily in nascent form. Nevertheless, it is hoped that the model will stimulate further research and hence ongoing development and refinement of theories and treatments regarding the interpersonal aspects of eating disorders.

Since our IPT-ED model highlights the centrality of actual or perceived negative social evaluation in the maintenance of eating disorders symptoms, a priority for future research will be attempting to further elucidate this construct and the mechanisms by which it is associated with eating disorder symptoms. In addition to the explicit hypotheses presented in the IPT-ED model, numerous questions remain. For instance, both social acceptance and social status are complex constructs (i.e., acceptance includes liking and support while social 
status includes respect, prestige, influence, and attention), such that research is needed to identify the relevant components for eating disorders. Similarly, the relative importance of social acceptance versus social status in driving eating disorder symptoms remains unknown, as does the issue regarding the sources of social validation that are most important for individuals with an eating disorder. For example, it has been proposed that individuals may be differentially oriented towards positive social evaluation from intimate others versus the broader social sphere (Baumeister \& Sommer, 1997). Also requiring investigation are refinements to the model to account for differences in the development, maintenance, and treatment of the various eating disorders. As just one possible example, autism spectrum disorders have been found to be over-represented among individuals with chronic anorexia nervosa (Wentz, Gillberg, Anckarsäter, Gillberg, \& Råstam, 2009; Zucker et al., 2007). Although the range of social deficits characterizing the autism spectrum disorders are highly variable across affected individuals and are not yet delineated for those with chronic anorexia nervosa, this overlap suggests that the IPT-ED model may need to be expanded for some types of anorexia nervosa to highlight the deficits in socialcognitive skills (e.g., low novelty seeking) that impede the individual's capacity to create and experience validating social interactions.

An IPT intervention informed by the IPT-ED model proposed here would primarily seek to assist the patient to establish a sense of the self as embedded within an accepting, supporting, and respecting social context that provides a viable alternative to the eating disorder in seeking positive esteem and affect. The key treatment implications of our model for conducting IPT in the treatment of eating disorders include providing a formulation accounting for the connection between interpersonal problems and eating disorder symptoms for therapists and patients alike, providing a rationale for attending to the social evaluative dimensions of eating disorder relevant constructs (such as perfectionism), and highlighting the need to target negative social evaluation as a key component of treatment. It is hoped that emphasizing the need to address this central construct will help to focus the work of therapy, with previous reports of an inordinate amount of treatment being taken up by attempts to identify the treatment focus (McIntosh et al., 2005). Patients may need considerable support to overcome any fear- and futility-based resistance to the notion that they can attain a sense of value and affect regulation in the absence of the eating disorder and through traversing the less predictable world of interpersonal relationships. They are also likely to need assistance to move beyond the language of eating, shape, and weight, since a predominant focus on these concerns will serve to solidify the asocial solution of the person with an eating disorder.

\section{References}

Agras, W. S., Walsh, T., Fairburn, C. G., Wilson, G. T., \& Kraemer, H. C. (2000). A multicenter comparison of cognitive-behavioral therapy and interpersonal psychotherapy for bulimia nervosa. Archives of General Psychiatry, 57, 459-466.

Alden, L. E., Wiggins, J. S., \& Pincus, A. L. (1990). Construction of circumplex scales for the Inventory of Interpersonal Problems. Journal of Personality Assessment, 55, 521-536.

Anderson, C., John, O. P., Keltner, D., \& Kring, A. M. (2001). Who attains social status? Effects of personality and physical attractiveness in social groups. Journal of Personality and Social Psychology, 81, 116-132.

Anderson, C., Srivastava, S., Beer, J. S., Spataro, S. E., \& Chatman, J. A. (2006). Knowing your place: Self-perceptions of status in face-to-face groups. Journal of Personality and Social Psychology, 91, 1094-1110.

Apple, R. (1999). Interpersonal therapy for bulimia nervosa. Journal of Clinical Psychology, 55, 715-725.

Arcelus, J., Whight, D., Langham, C., Baggott, J., McGrain, L., Meadows, L., \& Meyer, C. (2009). A case series evaluation of a modified version of interpersonal psychotherapy (IPT) for the treatment of bulimic eating disorders: A pilot study. European Eating Disorders Review, 17, 260-268

Barkow, J. H. (1975). Prestige and culture: A biosocial interpretation. Current Anthropology, $16,553-562$.

Baumeister, R. F., DeWall, C. N., Ciarocco, N. J., \& Twenge, J. M. (2005). Social exclusion impairs self-regulation. Journal of Personality and Social Psychology, 88, 589-604.

Baumeister, R. F., \& Sommer, K. L. (1997). What do men want? Gender differences and two spheres of belongingness: Comment on Cross and Madson (1997). Psychological Bulletin, 122, 38-44.
Baumeister, R. F., \& Vohs, K.D. (2003). Self-regulation and the executive function of the self In M. R. Leary \& J.P. Tangney (Eds.), Handbook of self and identity (pp. 197-217). New York: Guilford Press.

Benjamin, L. S., Rothweiler, J. C., \& Critchfield, K. L. (2006). The use of structural analysis of social behaviour (SASB) as an assessment tool. Annual Review of Clinical Psychology, 2, $83-109$.

Bell, R. M. (1985). Holy anorexia. Chicago: University of Chicago Press.

Besser, A., Flett, G. L., \& Davis, R. A. (2003). Self-criticism, dependency, silencing the self, and loneliness: A test of a mediational model. Personality and Individual Differences, $35,1735-1752$.

Birchall, H. (1999). Interpersonal psychotherapy in the treatment of eating disorders. European Eating Disorders Review, 7, 315-320.

Bruch, H. (1973). Eating disorders: Obesity, anorexia nervosa, and the person within. London: Routledge and Kegan Paul.

Bowlby, J. (1977). The making and breaking of affectional bonds: Aetiology and psychopathology in the light of attachment theory. British Journal of Psychiatry, 130, $201-210$.

Boyes, A. D., Fletcher, G. J. O., \& Latner, J. (2007). Male and female body image and dieting in the context of intimate relationships. Journal of Family Psychology, 21, $764-768$.

Burton, E., Stice, E., Bearman, S. K., \& Rohde, P. (2007). Experimental test of the affectregulation theory of bulimic symptoms and substance use: A randomized trial. International Journal of Eating Disorders, 40, 27-36.

Cockell, S. J., Geller, J., \& Linden, W. (2002). The development of a decisional balance scale for anorexia nervosa. European Eating Disorders Review, 10, 359-375.

Collins, W. A., \& Steinberg, L. (2006). Adolescent development in interpersonal context. In W. Damon \& R.M. Lerner, 6th ed. Handbook of child psychology, Vol. 3. (pp. 1003-1067). New York: John Wiley.

Cooper, M. J., Wells, A., \& Todd, G. (2004). A cognitive model of bulimia nervosa. British Journal of Clinical Psychology, 43, 1-16.

Crafti, N. A. (2002). Integrating cognitive-behavioural and interpersonal approaches in a group program for the eating disorders: Measuring effectiveness in a naturalistic setting. Behaviour Change, 19, 22-38.

Cramer, K. M., Gallant, M. D., \& Langlois, M. W. (2005). Self-silencing and depression in women and men: Comparative structural equation models. Personality and Individual Differences, 39, 581-592.

Crisp, A. H. (1980). Anorexia nervosa: Let me be. Sydney: Academic Press.

Crocker, J., Luhtanen, R. K., Cooper, M. L., \& Bouvrette, A. (2003). Contingencies of self worth in college students: Theory and measurement. Journal of Personality and Social Psychology, 85, 894-908.

Crocker, J., \& Wolfe, C. T. (2001). Contingencies of self worth. Psychological Review, 108, $593-623$.

Dohnt, H., \& Tiggemann, M. (2006). The contribution of peer and media influences to the development of body satisfaction and self esteem in young girls: A prospective study. Developmental Psychology, 42, 929-936.

Downey, G., \& Feldman, S. I. (1996). Implications of rejection sensitivity for intimate relationships. Journal of Personality and Social Psychology, 70, 1327-1343.

Downey, G., Freitas, A. L., Michaelis, B., \& Khouri, H. (1998). The self-fulfilling prophecy in close relationships: Rejection sensitivity and rejection by romantic partners. Journal of Personality and Social Psychology, 75, 545-560.

Eisler, I. (1995). Family models of eating disorders. In G. Szmukler, C. Dare, \& J. Treasure (Eds.), Handbook of eating disorders: Theory, treatment and research (pp. 155-176). London: John Wiley.

Eisler, I. (2005). The empirical and theoretical base of family therapy and multiple family day therapy for adolescent anorexia nervosa. Journal of Family Therapy, 27, 104-131.

Eskildsen, S. (1998). Asceticism in early Taoist religion. New York: State University of New York Press.

Fairburn, C. G. (1985). Cognitive behavioral treatment for bulimia. In D. M. Garner \& P.E Garfinkel (Eds.), Handbook of psychotherapy for anorexia nervosa and bulimia (pp. 160-192). New York: Guilford Press.

Fairburn, C. G., Cooper, Z., Doll, H. A., \& Welch, S. L. (1999). Risk factors for anorexia nervosa: Three integrated case-control comparisons. Archives of General Psychiatry, $56,468-476$.

Fairburn, C. G., Cooper, Z., \& Shafran, R. (2003). Cognitive behavioral therapy for eating disorders: A "transdiagnostic" theory and treatment. Behaviour Research and Therapy, $41,509-528$.

Fairburn, C. G., Doll, H. A., Welch, S. L., Hay, P. J., Davies, B. A., \& O'Connor, M. E. (1998) Risk factors for binge eating disorder: A community-based, case-control study. Archives of General Psychiatry, 55, 425-432.

Fairburn, C. G., Jones, R., Peveler, R. C., Carr, S. J., Solomon, R. A., O'Connor, M. E., et al. (1991). Three psychological treatments for bulimia nervosa. A comparative trial. Archives of General Psychiatry, 48, 463-469.

Fairburn, C. G., Welch, S. L., Doll, H. A., Davies, B. A., \& O'Connor, M. E. (1997). Risk factors for bulimia nervosa: A community-based case-control study. Archives of General Psychiatry, 54, 509-517.

Frank, E., \& Spanier, C. (1995). Interpersonal psychotherapy for depression: Overview, clinical efficacy, and future directions. Clinical Psychology: Science and Practice, 2, 349-369.

Geller, J., Cockell, S. J., Hewitt, P., Goldner, E. M., \& Flett, G. (2000). Inhibited expression of negative emotions and interpersonal orientation in anorexia nervosa. International Journal of Eating Disorders, 28, 8-19.

Geller, J., Johnston, C., \& Madsen, K. (1997). The role of shape and weight in selfconcept: The Shape and Weight Based Self-Esteem Inventory. Cognitive Therapy and Research, 21, 5-24.

Gerner, B., \& Wilson, P. H. (2005). The relationship between friendship factors and adolescent girls' body image concern, body dissatisfaction, and restrained eating. International Journal of Eating Disorders, 37, 313-320. 
Gilbert, N., \& Meyer, C. (2005). Fear of negative evaluation and the development of eating psychopathology: A longitudinal study among nonclinical women. International Journal of Eating Disorders, 37, 307-312.

Godart, N., Flament, M., Lecrubier, Y., \& Jeammet, P. (2000). Anxiety disorders in anorexia nervosa and bulimia nervosa: Co-morbidity and chronology of appearance. European Psychiatry, 15, 38-45.

Griffin, D., \& Bartholomew, K. (1994). Models of self and other: Fundamental dimensions underlying measures of adult attachment. Journal of Personality and Social Psychology, 67, 430-445.

Grissett, N. I., \& Norvell, N. K. (1992). Perceived social support, social skills, and quality of relationships in bulimic women. Journal of Consulting and Clinical Psychology, 60, $293-299$.

Gross, J. J., \& John, O. P. (2003). Individual differences in two emotion regulation processes: Implications for affect, relationships, and wellbeing. Journal of Personality and Social Psychology, 85, 348-362.

Gross, J. J., Richards, J. M., \& John, O. P. (2006). Emotion regulation in everyday life. In D. K. Snyder, J. A. Simpson, \& J. N. Hughes (Eds.), Emotion regulation in couples and families: Pathways to dysfunction and health (pp. 13-35). Washington DC: American Psychological Association.

Gurtman, M. B. (2001). Interpersonal complementarity: Integrating interpersonal measurement with interpersonal models. Journal of Counseling Psychology, 48, 97-110.

Harter, S. (1999). The construction of the self: A developmental perspective. New York: Guilford Press.

Harter, S. (2006). The self. In W. Damon \& R.M. Lerner, 6th ed. Handbook of child psychology, Vol. 3. (pp. 505-570). New York: John Wiley.

Heatherton, T. F., \& Baumeister, R. F. (1991). Binge eating as an escape from self awareness. Psychological Bulletin, 110, 86-108.

Hesse-Biber, S., Leavy, P., Quinn, C. E., \& Zoino, J. (2006). The mass marketing of disordered eating and eating disorders: The social psychology of women, thinness and culture. Women's Studies International Forum, 29, 208-224.

Hewitt, P. L., Flett, G. L., Besser, A., Sherry, S. B., \& McGee, B. (2003). Perfectionism is multidimensional: A reply to Shafran, Cooper and Fairburn. Behaviour Research and Therapy, 41, 1221-1236.

Hinrichson, H., Wright, F., Waller, G., \& Meyer, C. (2003). Social anxiety and coping strategies in the eating disorders. Eating Behaviors, 4, 117-126.

Hohlstein, L. A., Smith, G. T., \& Atlas, J. G. (1998). An application of expectancy theory to eating disorders: Development and validation of measures of eating and dieting expectancies. Psychological Assessment, 10, 49-58.

Hooley, J. M., \& Teasdale, J. D. (1989). Predictors of relapse in unipolar depressives: Expressed emotion, marital distress, and perceived criticism. Journal of Abnormal Psychology, 98, 229-235.

Jack, D. C., \& Dill, D. (1992). The Silencing the Self Scale: Schemas of intimacy associated with depression in women. Psychology of Women Quarterly, 16, 97-106.

Jacobs, M. J., Welch, R., \& Wilfley, D. (2004). Interpersonal therapy for anorexia nervosa, bulimia nervosa, and binge eating disorder. In T. D. Brewerton (Ed.), Clinical handbook of eating disorders: An integrated approach. Abingdon: Informa Health Care.

Kernis, M. H., Cornell, D. P., Sun, C. R., Berry, A., \& Harlow, T. (1993). There's more to self esteem that whether it's high or low: The importance of stability of self-esteem. Journal of Personality and Social Psychology, 65, 1190-1204.

Klerman, G. L., Weissman, M. M., Rounsaville, B. J., \& Chevron, E. S. (1984). Interpersonal psychotherapy of depression. New York: Basic Books.

Krones, P. G., Stice, E., Batres, C., \& Orjada, K. (2005). In vivo comparison to a thin-ideal peer promotes body dissatisfaction: A randomized experiment. International Journal of Eating Disorders, 38, 134-142.

Laessle, R., Wittchen, H., Fichter, M., \& Pirke, K. (1989). The significance of subgroup of bulimia and anorexia nervosa: Lifetime frequency of psychiatric disorders. International Journal of Eating Disorders, 8, 569-574.

Lattimore, P. J., Wagner, H. L., \& Gowers, S. (2000). Conflict avoidance in anorexia nervosa: An observational study of mothers and daughters. European Eating Disorders Review, 8, 355-368.

Leary, M. R., \& Baumeister, R. F. (2000). The nature and function of self-esteem: Sociometer theory. In M. P. Zanna (Ed.), Advances in experimental social psychology, Vol. 32. (pp. 1-62)San Diego: Academic Press.

Leary, M. R., Cottrell, C. A., \& Phillips, M. (2001). Deconfounding the effects of dominance and social acceptance on self esteem. Journal of Personality and Social Psychology, 81, 898-909.

Leary, M. R., Haupt, A. L., Strausser, K. S., \& Chokel, J. T. (1998). Calibrating the sociometer: The relationship between interpersonal appraisals and state selfesteem. Journal of Personality and Social Psychology, 74, 1290-1299.

Lock, J., \& le Grange, D. (2005). Family-based treatment of eating disorders. International Journal of Eating Disorders, 37, S64-S67.

MacDonald, G., Saltzman, J. L., \& Leary, M. R. (2003). Social approval and trait self esteem. Journal of Research in Personality, 37, 23-40.

Maharaj, S., Rodin, G., Connolly, J., Olmsted, M., \& Denis, D. (2001). Eating problems and observed quality of mother-daughter interactions among girls with type 1 diabetes. Journal of Consulting and Clinical psychology, 69, 950-958.

Markowitz, J. C. (2003). Interpersonal psychotherapy for chronic depression. JCLP/In Session, 59, 847-858.

Markowitz, J. C., Skodol, A. E., \& Bleiberg, K. (2006). Interpersonal psychotherapy for borderline personality disorder: Possible mechanisms of change. Journal of Clinical Psychology, 62, 431-444.

May, A. L., Kim, J. Y., McHale, S. M., \& Crouter, A. C. (2006). Parent-adolescent relationships and the development of weight concerns from early to late adolescence. International Journal of Eating Disorders, 39, 729-740.
McClintock, J. M., \& Evans, I. M. (2001). The underlying psychopathology of eating disorders and social phobia: A structural equation analysis. Eating Behaviors, 2, $247-261$.

McIntosh, V. V. W., Jordan, J., Carter, F. A., Luty, S. E., McKenzie, J. M., Bulik, C. M., et al. (2005). Three psychotherapies for anorexia nervosa: A randomised, controlled trial. American Journal of Psychiatry, 162, 741-747.

McIntosh, V. V. W., Jordan, J., Luty, S. E., Carter, F. A., McKenzie, J. M., Bulik, C. M., et al. (2006). Specialist supportive clinical management for anorexia nervosa. International Journal of Eating Disorders, 39, 625-632.

Mead, G. H. (1934). Mind, self, and society. Chicago: University of Chicago Press.

Nielsen, S., \& Bará-Carril, N. (2003). Family, burden of care and social consequences. In J. Treasure, U. Schmidt \& E. van Furth (Eds.), Handbook of eating disorders: Theory, treatment and research (pp. 191-206)., 2nd ed. Chichester: John Wiley.

Nolen-Hoeksema, S. (1991). Responses to depression and their effects on the duration of depressive episodes. Journal of Abnormal Psychology, 100, 569-582.

Nordbø, R. H. S., Espeset, E. M., Gulliksen, K. S., Skårderud, F., \& Holte, A. (2006). The meaning of self-starvation: Qualitative study of patients' perception of anorexia nervosa. International Journal of Eating Disorders, 39, 556-564.

Oates-Johnson, T., \& Clark, D. A. (2004). Sociotropy, body dissatisfaction and perceived social disapproval in dieting women: A prospective diathesis-stress study of dysphoria. Cognitive Therapy and Research, 28, 715-731.

Okon, D. M., Greene, A. L., \& Smith, J. E. (2002). Family interactions predict intraindividual symptom variation for adolescents with bulimia. International Journal of Eating Disorders, 34, 450-457.

Oliver, K. G., Huon, G. F., Zadro, L., \& Williams, K. D. (2001). The role of interpersonal stress in overeating among high and low disinhibitors. Eating Behaviors, 2, 19-26.

Paxton, S. J., Schutz, H. K., Wertheim, E. H., \& Muir, S. L. (1999). Friendship clique and peer influences on body image concerns, dietary restraint, extreme weight-loss behaviors, and binge eating in adolescent girls. Journal of Abnormal Psychology, 108, 255-266.

Perry, J. A., Silvera, D. H., Neilands, T. B., Rosenvinge, J. H., \& Hanssen, T. (2008). A study of the relationship between parental bonding, self-concept and eating disturbances in Norwegian and American college populations. Eating Behaviors, 9, 13-24.

Peterson, C., Wonderlich, S., Mitchell, J., \& Crow, S. (2004). Integrative cognitive therapy for bulimia nervosa. In J. K. Thompson (Ed.), Handbook of eating disorders and obesity (pp. 245-262). Hoboken: Wiley.

Pike, K. M., Hilbert, A., Wilfley, D. E., Fairburn, C. G., Dohm, F. -A., Walsh, B. T., et al. (2007). Toward an understanding of risk factors for anorexia nervosa: A casecontrol study. Psychological Medicine. doi:10.1017/S0033291707002310

Piran, N., Kennedy, S., Garfinkel, P., \& Owens, M. (1985). Affective disturbance and eating disorders. Journal of Nervous and Mental Disease, 173, 395-400.

Polivy, J., \& Herman, C. P. (2002). Causes of eating disorders. Annual Review of Psychology, 53, 187-213.

Poser, M. (2005a). Anorexia nervosa-My story. Journal of Family Therapy, 27, 142-143.

Poser, M. (2005b). Anorexia nervosa-A parent's perspective. Journal of Family Therapy, 27, $144-146$

Puhl, R. M., \& Brownell, K. D. (2003). Psychosocial origins of obesity stigma: Toward changing a powerful and pervasive bias. Obesity Reviews, 4, 213-227.

Reijntjes, A., Stegge, H., Terwogt, M. M., Kamphuis, J. H., \& Telch, M. J. (2006). Emotion regulation and its effects on mood improvement in response to an in vivo peer rejection challenge. Emotion, 6, 543-552.

Rubin, K. H., Bukowski, W., \& Parker, J. G. (1998). Peer interactions, relationships, and groups. In W. Damon, 5th ed. Handbook of child psychology, Vol. 3, New York: John Wiley.

Schmidt, U., \& Treasure, J. (2006). Anorexia nervosa: Valued and visible. A cognitiveinterpersonal maintenance model and its implications for research and practice. British Journal of Clinical Psychology, 45, 343-366.

Serpell, L., Treasure, J., Teasdale, J., \& Sullivan, V. (1999). Anorexia nervosa: Friend or Foe? International Journal of Eating Disorders, 25, 177-186.

Serpell, L., \& Treasure, J. (2002). Bulimia nervosa: Friend or foe? The pros and cons of bulimia nervosa. International Journal of Eating Disorders, 32, 164-170.

Shafran, R., Cooper, Z., \& Fairburn, C. G. (2003). "Clinical perfectionism" is not "multidimensional perfectionism": A reply to Hewitt, Flett, Besser, Sherry \& McGee. Behaviour Research and Therapy, 41, 773-791.

Shafran, R., Cooper, Z., \& Fairburn, C. G. (2002). Clinical perfectionism: A cognitivebehavioural analysis. Behaviour Research and Therapy, 40, 773-791.

Shroff, H., \& Thompson, J. K. (2006). Peer influences, body image dissatisfaction, eating dysfunction and self esteem in adolescent girls. Journal of Health Psychology, 11, $533-551$.

Smolak, L., Levine, M. P., \& Schermer, F. (1999). Parental input and weight concern among elementary school children. International Journal of Eating Disorders, 25, $263-271$.

Srivastava, S., \& Beer, J. S. (2005). How self evaluations relate to being liked by others: Integrating sociometer and attachment perspectives. Journal of Personality and Social Psychology, 89, 966-977.

Steiger, H., Guavin, L., Jabalpurwala, S., Séguin, J. R., \& Stotland, S. (1999). Hypersensitivity to social interactions in bulimic syndromes: Relationship to binge eating. Journal of Consulting and Clinical Psychology, 67, 765-775.

Stice, E. (2002). Risk and maintenance factors for eating pathology: A meta-analytic review. Psychological Bulletin, 128, 825-848.

Striegel-Moore, R. H., Fairburn, C. G., Wilfley, D. E. Pike, K. M., Dohm, F. -A. \& Kraemer, H. C. (2005). Toward an understanding of risk factors for binge-eating disorder in black and white women: A community-based case-control study. Psychological Medicine, 35, 907-917.

Stroud, L. R., Tanofsky-Kraff, M., Wilfley, D. E., \& Salovey, P. (2000). The Yale Interpersonal Stressor (YIPS): Affective, physiological, and behavioral responses 
to a novel interpersonal rejection paradigm. Annals of Behavioral Medicine, 22, 204-213.

Stuart, S., \& Robertson, M. (2003). Interpersonal psychotherapy: A clinician's guide. London: Arnold.

Swann, W. B., Griffin, J. J., Predmore, S. C. \& Gaines, B. (1987). The cognitive-affective crossfire: When self-consistency confronts self-enhancement. Journal of Personality and Social Psychology, 52, 881-889.

Swartz, H. A. (1999). Interpersonal psychotherapy. In M. Hersen, \& A. S. Bellack (Eds.) Handbook of comparative interventions for adult disorders (pp. 139-155). New York: John Wiley.

Tanofsky-Kraff, M., \& Wilfley, D. E. (in press). Interpersonal psychotherapy for eating disorders. In W. S. Agras (Ed.), Oxford handbook of eating disorders. Oxford: Oxford University Press.

Tanofsky-Kraff, M., Wilfley, D. E., \& Spurrell, E. (2000). Impact of interpersonal and egorelated stress on restrained eaters. International Journal of Eating Disorders, 27, 411-418.

Tantleff-Dunn, S., Gokee-LaRose, J., \& Peterson, R. D. (2004). Interpersonal psychotherapy for the treatment of anorexia nervosa, bulimia nervosa, and binge eating disorder. In J. K. Thompson (Ed.), Handbook of eating disorders and obesity (pp. 163-185). New York: John Wiley.

Tesser, A. (2003). Self-evaluation. In M. R. Leary, \& J. P. Tangney (Eds.), Handbook of self and identity (pp. 275-290). New York: Guilford Press.

Tesser, A., Crepaz, N., Collins, J. C., Cornell, D., \& Beach, S. R. H. (2000). Confluence of self esteem regulation mechanisms: On integrating the self-zoo. Personality and Social Psychology Bulletin, 26, 1476-1489.

Tiller, J. M., Sloane, G., Schmidt, U., Troop, N., Power, M., \& Treasure, J. L. (1997). Social support in patients with anorexia nervosa and bulimia nervosa. International Journal of Eating Disorders, 21, 31-38.

Tuschen-Caffier, B., \& Vögele, C. (1999). Psychological and physiological reactivity to stress: An experimental study on bulimic patients, restrained eaters and controls. Psychotherapy and Psychosomatics, 68, 333-340.

Van Buren, D. J., \& Williamson, D. A. (1988). Marital relationships and conflict resolution skills of bulimics. International Journal of Eating Disorders, 7, 735-741.

Van den Brouke, S., Vandereycken, W., \& Norré, J. (1997). Eating disorders and marital relationships. London: Routledge.

van Furth, E. F., van Strien, D. C., Martina, L. M. L., van Son, M. J. M., Hendrickx, J. J. P., \& van Engeland, H. (1996). Expressed emotion and the prediction of outcome in adolescent eating disorders. International Journal of Eating Disorders, 20, 19-31.

Vitousek, K. B., \& Hollon, S. D. (1990). The investigation of schematic content and processing in eating disorders. Cognitive Therapy and Research, 14, 191-214.

Vitousek, K., Watson, S., \& Wilson, G. T. (1998). Enhancing motivation for change in treatment-resistant eating disorders. Clinical Psychology Review, 18, 391-420.

Wade, T. D., \& Lowes, J. (2002). Variables associated with disturbed eating habits and overvalued ideas about the personal implications of body shape and weight in female adolescent population. International Journal of Eating Disorders, 32, 39-45.
Waller, G., Babbs, M., Milligan, R., Meyer, C., Ohanian, V., \& Leung, N. (2003). Anger and core beliefs in eating disorders. International Journal of Eating Disorders, 34, 118-124.

Watson, D., \& Friend, R. (1969). Measurement of social-evaluative anxiety. Journal of Consulting and Clinical Psychology, 33, 448-457.

Weissman, M. M. (2007). Cognitive therapy and interpersonal psychotherapy: 30 years later. American Journal of Psychiatry, 164, 693-696.

Weissman, M. M., Markowitz, J. C., \& Klerman, G. L. (2000). Comprehensive guide to interpersonal psychotherapy. New York: Basic Books.

Wentz, E., Gillberg, C., Anckarsäter, H., Gillberg, C., \& Råstam, M. (2009). Adolescent-onset anorexia nervosa: 18-year outcome. British Journal of Psychiatry, 194, 168-174.

Wilfley, D. E., Agras, W. S., Telch, C. F., Rossiter, E. M., Schneider, J. A., Cole, A. G., et al. (1993). Group cognitive-behavioral therapy and group interpersonal psychotherapy for the nonpurging bulimic individual: A controlled comparison. Journal of Consulting and Clinical Psychology, 61, 296-305.

Wilfley, D. E., MacKenzie, K. R., Welch, R. R., Ayres, V. E., \& Weissman, M. M. (2000). Interpersonal psychotherapy for group. New York: Basic Books.

Wilfley, D. E., Pike, K. M., \& Striegel-Moore, R. H. (1997). Toward an integrated model of risk for binge eating disorder. Journal of Gender, Culture, and Health, 2, 1-32.

Wilfley, D. E., Stein, R. \& Welch, R. (2003). Interpersonal psychotherapy. In J. Treasure, U. Schmidt \& E. van Furth (Eds.), Handbook of eating disorders (pp. 253-270)., 2nd ed. Chichester: John Wiley.

Wilfley, D. E., Welch, R. R., Stein, R. I., Spurrell, E. B., Cohen, L. R., Saelens, B. E., et al. (2002). A randomized comparison of group cognitive-behavioral therapy and group interpersonal psychotherapy for the treatment of overweight individuals with binge eating disorder. Archives of General Psychiatry, 59, 713-721.

Williams, K. D., Cheung, C. K. T., \& Choi, W. (2000). Cyberostracism: Effects of being ignored over the internet. Journal of Personality and Social Psychology, 79, 748-762.

Wilson, G. T. (2005). Psychological treatment of eating disorders. Annual Review of Clinical Psychology, 1, 439-465.

Wilson, G. T., Wilfley, D. E., Agras, W. S., \& Bryson, S. W. (2010). Psychological treatments of binge eating disorder. Archives of General Psychiatry, 67, 94-101.

Wood, J. V. (1989). Theory and research concerning social comparisons of personal attributes. Psychological Bulletin, 22, 231-248.

Wood, J. V., \& Wilson, A. E. (2003). How important is social comparison? In M. R. Leary \& J.P. Tangney (Eds.), Handbook of self and identity (pp. 344-366). New York: Guilford Press.

World Health Organization. (1998). Obesity-Preventing and managing a global epidemic: Report of a WHO consultation on obesity. Geneva: Author.

Zucker, N. L, Losh, M., Bulik, C. M., LaBar, K. S., Piven, J., \& Pelphrey, K. A. (2007) Anorexia nervosa and autistic spectrum disorders: Guided investigation of social cognitive endophenotypes. Psychological Bulletin, 133, 976-1006. 